\title{
Correspondence
}

\section{Doses of carbamazepine and valproate in bipolar affective disorder}

Sir: Taylor \& Duncan (Psychiatric Bulletin, April 1997, 21, 221-223) make clinical recommendations for dosing regimen and plasma levels of carbamazepine and sodium valproate in bipolar affective disorders based on a Medline search We believe that there are three areas in which this paper is inadequate.

First, the authors did not detail key words, search strategy or years of search. Whether or not the search was limited to English was not defined. This clearly detracts from the validity of the paper. The lack of a detailed methodology means that the literature search that they have carried out could not be easily reproduced by an independent researcher.

Second, although heterogeneity of treatment response is mentioned in the discussion, no attempt is made to explore the reasons for the variability in results between studies or validate the comparison of treatment responses between subtypes of bipolar disorder such as acute mania rapid-cycling bipolar and cyclothymia. Study design is not discussed and short-term open studies appear to be given equal weighting to double-blind studies. For example, equal weight is given to the information gleaned from the five double-blind studies concerned with the use of carbamazepine and the presumably open studies of valproate.

Third, there are intrinsic difficulties associated with Medline searches (Adams et al, 1994). To provide a complete systematic review of current research findings a Medline search would need to be supplemented by extensive hand searching. Relying solely on Medline searches will miss a large body of published literature including conference abstracts, 'grey' literature and dissertations. Unpublished data, bearing in mind a bias against 'negative' studies, will not be included in the review. There is no indication that any hand searching or supplementary information gathering was used in this study.

While this paper addresses an interesting and important area, we advise that its conclusions must only be regarded as preliminary in light of these methodological shortcomings.

Adams, O. E.. Power. A., Frederick, K. et al (1994) An investigation of the adequacy of MedLine Searches for randomised control trials (RCTs) of the efficacy of mental health care. Psychological Medicine, 24, 741-748.

J. B. Grace, Clinical Research Associate, and A. H. Young, Senior Lecturer and Honorary
Consultant in Psychiatry, Department of Psychiatry, Leazes Wing, Royal Victoria Infirmary, Newcastle upon Tyne

Authors' reply: This article was intended to be a brief review of the literature pertaining to the use of carbamazepine and valproate in bipolar disorder. An exhaustive critique was considered inappropriate for a practice-orientated journal such as the Bulletin.

Nevertheless, our search of the literature was broad. The Drug Information Centre at the Maudsley has a large library of drug-related references and we have ready access to Medline, PsychLit, and Micromedex. Moreover, members of the department visit all major conferences (American Psychiatric Association, European College of Neuropsycho-pharmacology. British Association for Psychopharmacology, Biological Psychiatry) and collect details of posters and abstracts. We examine the reference sections of all papers on file and then retrieve other relevant reports. As a consequence, our Medline searches usually only reveal that we have on file all Medline-referenced papers and many more besides.

Our search could not be reproduced by an independent researcher. This is partly because we did not specify search terms, but also because searches are time-dependent. In addition, our hand search was, as already described, extensive and was, by definition, not systematic or reproducible.

We reviewed studies for which full trial details were available. Our intention was to question normal prescribing practice for which there is virtually no support in the literature. The conclusions we drew are evidence-based, but preliminary, given the restricted nature of our article. We contend, however, that our conclusions are more cogent than current, unsupported dose recommendations.

DAVID TAYLOR, Chief Pharmacist, and DENISE DUNCAN, Senior Drug Information Pharmacist, Pharmacy Department, Maudsley Hospital, Denmark Hill, London SE5 8AZ

\section{Financial implications of Calman changes in paychiatry}

Sir: I am writing to highlight the discrepancy in the pay structure for trainees in psychiatry as a result of the Calman changes in postgraduate training. Presently there is a dichotomy among 
trainees with respect to our salary structure. Those trainees who passed the MRCPsych I before and including the Spring 1996 examination moved up to the (old) registrar pay scales. However, trainees who passed later examinations continue to stagnate at senior house officer (SHO) grades. Therefore at present trainees who do the same post-MRCPsych I jobs get paid vastly differing amounts.

Such a situation is unfair and discriminatory. I have been told that the discrepancy will work itself out of the system in a couple of years - a fact which is supposed to be a source of solace to myself and others who are at the receiving end of this inconsistency. Representations to the British Medical Association and the College have not proved helpful; surprising since both organisations are in no small way responsible for the present disparity.

Entwined with the above anomaly is the fact that unlike other specialities, in psychiatry one has to pass the Part II to enter the specialist grade. While I can understand the reasons I am not sure that full attention has been paid to the financial consequences of this decision. Trainees with previous experience, either in general practice or other specialities, find their previous training does not provide the financial advantage that it would have in the past. For such trainees (and this is a significant number) the four increments on the SHO scale are used up prior to or soon after joining a SHO post.

I wonder whether account is being taken of the very obvious negative effect the above anomalies are having on recruitment and morale. I am aware of general practitioners and trainees with a medical membership who were keen to train in psychiatry, but rethought their options once aware of the financial disadvantage.

I wonder how many other trainees are aware of and are affected by these changes. A concerted effort is needed if things are to change. I would be happy to receive information about the situation in other regions from trainees at the above address.

ZUBIN BHAGWAGAR, Wellcome Research Senior House Officer, Psychopharmacology Research Unit, Warneford Hospital, University of Oxford. Headington, Oxford OX3 7JX

College's reply: Dr Bhagwagar is angry because, through no fault of his own, he was unable to pass Part I of the MRCPsych in time to move onto the (old) registrar pay scale when the specialist registrar grade was introduced last year, and is therefore being paid a lower salary than many of his contemporaries for a couple of years. He is probably also annoyed by the failure of the College and the British Medical Association to do battle with the Department of Health on his behalf over this perceived injustice. He ought to know by now, though, that life is never perfectly fair. The introduction of any major change almost always had different implications for people born, or starting university, or qualifying. or getting married a few months apart, with arbitrary winners and losers.

I doubt whether this irritating temporary anomaly is really having the effect on morale and recruitment to psychiatry he suggests. It is quite true that psychiatry has a longer mandatory period of general professional training (three years) on a relatively low SHO salary than other disciplines. But it also has a shorter specialist training than any other discipline (three years. compared with five or six years in most of the other branches of hospital medicine) and that is surely more important in the long run. Dr Bhagwagar and other readers may also be interested to know that the Court of Electors recently agreed to reduce the length of time candidates for Part II of the MRCPsych must have spent in approved training posts from three years to two and a half (of which at least two years most have been in psychiatry). As a result the time he and his successors will need to spend as SHOs before becoming specialist registrars will also be reduced by six months.

R. E. KENDEll, President, Royal College of Psychiatrists, 17 Belgrave Square, London SW1X 8PG

\section{Educational supervision sessions between consultants and trainees}

Sir: The Royal College of Psychiatrists regards supervision as the "single most important ingredient of training" (Statement on Approval of Training Schemes for General Professional Training for the MRCPsych, 1992, available from the Postgraduate Education Services Department). It is therefore concerning to read Azuonye's findings that both consultants and trainees exhibited such a marked lack of understanding of the purpose of educational supervision (Psychiatric Bulletin, March 1997, 21, 154-155). We wish to draw attention to our very similar survey examining trainee supervision, previously published in the Bulletin (Herriot et al, 1994), in order to contrast our findings and comment on Azuonye's conclusions.

In contrast to the low response rates to Azuonye's questionnaire $142 \%$ of consultants and $52 \%$ of trainees), the response rate to our questionnaire was high $(83 \%$ of consultants and $67 \%$ of trainees). Whereas Azuonye found "the nature and purpose of supervision ... to be unclear to most consultants and trainees", we 